\title{
Surveying drinking water quality (Balikhlou River, Ardabil Province, Iran)
}

\author{
Mehdi Aalipour erdi ${ }^{1} \cdot$ Hassan Gasempour niari ${ }^{2} \cdot$ Seyyed Reza Mousavi Meshkini ${ }^{3} \cdot$ Somayeh Foroug $^{4}$
}

Received: 24 July 2015 / Accepted: 28 December 2017 / Published online: 8 February 2018

(c) The Author(s) 2018. This article is an open access publication

\begin{abstract}
Considering the importance of Balikhlou River as one of the most important water sources of Ardabil, Nir and Sarein cities, maintaining water quality of this river is the most important goals in provincial and national levels. This river includes a wide area that provides agricultural, industrial and drinking water for the residents. Thus, surveying the quality of this river is important in planning and managing of region. This study examined the quality of river through eight physicochemical parameters $\left(\mathrm{SO}^{4}, \mathrm{No}^{3}, \mathrm{BOD}_{5}, \mathrm{TDS}\right.$, turbidity, $\left.\mathrm{pH}, \mathrm{EC}, \mathrm{COD}\right)$ in two high- and low-water seasons by international and national standards in 2013. For this purpose, a review along the river has been done in five stations using $t$ test and SPSS software. Model results showed that the amount difference in TDS and EC with WHO standards, and TDS rates with Iran standards in low-water seasons, $\mathrm{pH}$ and EC with WHO standards in high-water seasons, is not significant in high-water season; but for $\mathrm{pH}$ and $\mathrm{SO}^{4}$ parameters, turbidity and $\mathrm{NO}^{3}$ in both standards and $\mathrm{EC}$ value with WHO standard in low-water season and $\mathrm{pH}, \mathrm{EC}, \mathrm{SO}^{4}$ parameters and turbidity and $\mathrm{NO}^{3}$ in high-water season have significant difference from 5 to $1 \%$, this shows the ideal limit and lowness of parameters for different usage.
\end{abstract}

Keywords Balikhlou River · Physicochemical $\cdot$ Iran and WHO standards

\section{Introduction}

In several years and during the past decades, at various levels, due to extensive human intervention, attitudes changed towards sustainable management of water resources (Meybeck 2003). The river as vital role in all aspects of human life and health has great impact in future of humanity. The need for water in agricultural, industry and drinking water demand has been increased by population growth and water demand; that imposed many pressure to water resources, while wate is needed for any development (Sedaghat 2008).

Mehdi Aalipour erdi

maalipour@ut.ac.ir

1 Candidate of Environment-Environmental Evaluation, Faculty of Natural Resources, University of Tehran, Tehran, Iran

2 Environmental Pollution, Islamic Azad University, Ardabil Branch, Ardabil, Iran

3 Agricultural Ecology, Department of Environment, Zanjan Head of Staff, Zanjan, Iran

4 Computer Engineering-Software, Islamic Azad University, Ardabil Branch, Ardabil, Iran
Water quality characteristics are components that considered the necessity of water resource management and the health of aquifer areas (Khadam and Kaluarachchi 2006). Nowadays, the water quality is the main issue in the case of surface water. Due to the use of the river waterway in the transfer of industrial sewage, agricultural and fruit plantations, these sources are imposed by different pollutions. Increase in the information about the quality of drinking water for public health and quality of raw water for aquatic life increased the need to survey the quality of surface water (Ouyang, 2005). The quality of surface water in a region is under influence of two agents: natural processes (rate of sedimentation, soil and water conditions and soil corrosive) and human processes such as agricultural and industrial activities (Huang and Chen 2009).

Today, the necessity of qualitative studies of water resources due to the wide variety of contaminant arrivals is inevitable and in most parts of the world is one of the most important challenges faced by humankind during recent years. During the recent decades, several solutions at different stages, identification, prevention and corrective actions, are presented by various researchers to increase the quality of the water resources. Rajaee and et al. studied drinking 


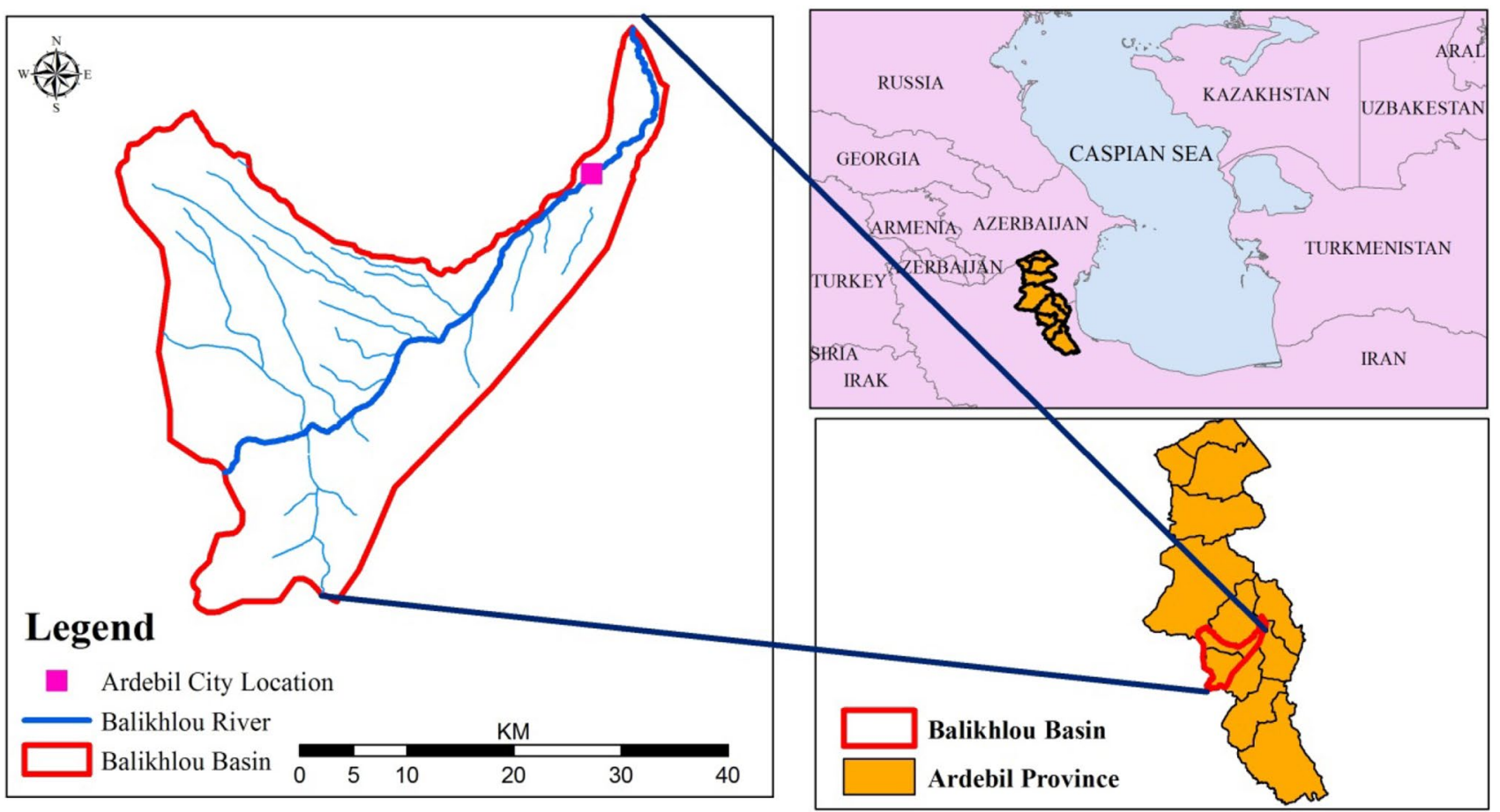

Fig. 1 The location of the study area in Ardabil Province and Iran

water wells quality on Ali Abad Katoul plain, they measured significant relationship between metal concentration and did not view any correlation between them on national and international standards (Rajaei et al. 2012). Miranzadeh et al. (2011) to study the concentrations of heavy metals (chromium, copper, zinc, lead, cobalt, silver, nickel, cadmium) in the five areas of water distribution network of Kashan city (in 2010) measured 35 samples in three seasons of spring, summer, autumn that approximately measured 105 samples which were higher than national and international standards.

Among them, identification and informative stage of the status of water resource quality as the first step in the direction of a healthy environment and access to water is a major source of studies and enough attention can be appropriate for the prevention and remedial measures to increase the quality of water resources (Nouri et al., 2011). In addition to the increasing world population, increased water usage has not only reduced the quantity of water available and has met with more restrictions, but also caused pollution and reduction in the quality of water resources (Hajian nejad and Rahsepar 2010).

Various human activities around rivers' privacy led to the entry of many pollutants into water canvas and affected the quality of river waters (Chen and Chen 2001). Considering the importance of the Balikhlou River as one of the most important sources of drinking water supply in Ardabil, Nir and Sarein cities, maintaining the water quality is one of the most important objectives of this non-notable alternative source. The most important action and management necessity in this regard is continuous knowledge about water quality of different stations. That means that with continuous measurements of index parameters of water quality for drinking consumption, and even its prediction for the future, must be sure the quality of these parameters in comparison with specified standards and if identified a non-authorized pollutants, timely find the source and recovery it. This river includes a wide area and provides agricultural and industrial water for the residents; thus, qualitative studies of the river are necessary for planning and optimum management of water resources.

\section{Methods}

\section{Study area}

The Balikhlou River is one of the most important rivers of Ardabil Province and is the most important and main branches of Gharesou River. Natural springs, rivers, snow water and rain water are main feeding sources of the river. This enters into the Ardabil city from the east. The north scope of the area is the Sabalan Mountain, in the west and south are Bozghosh 


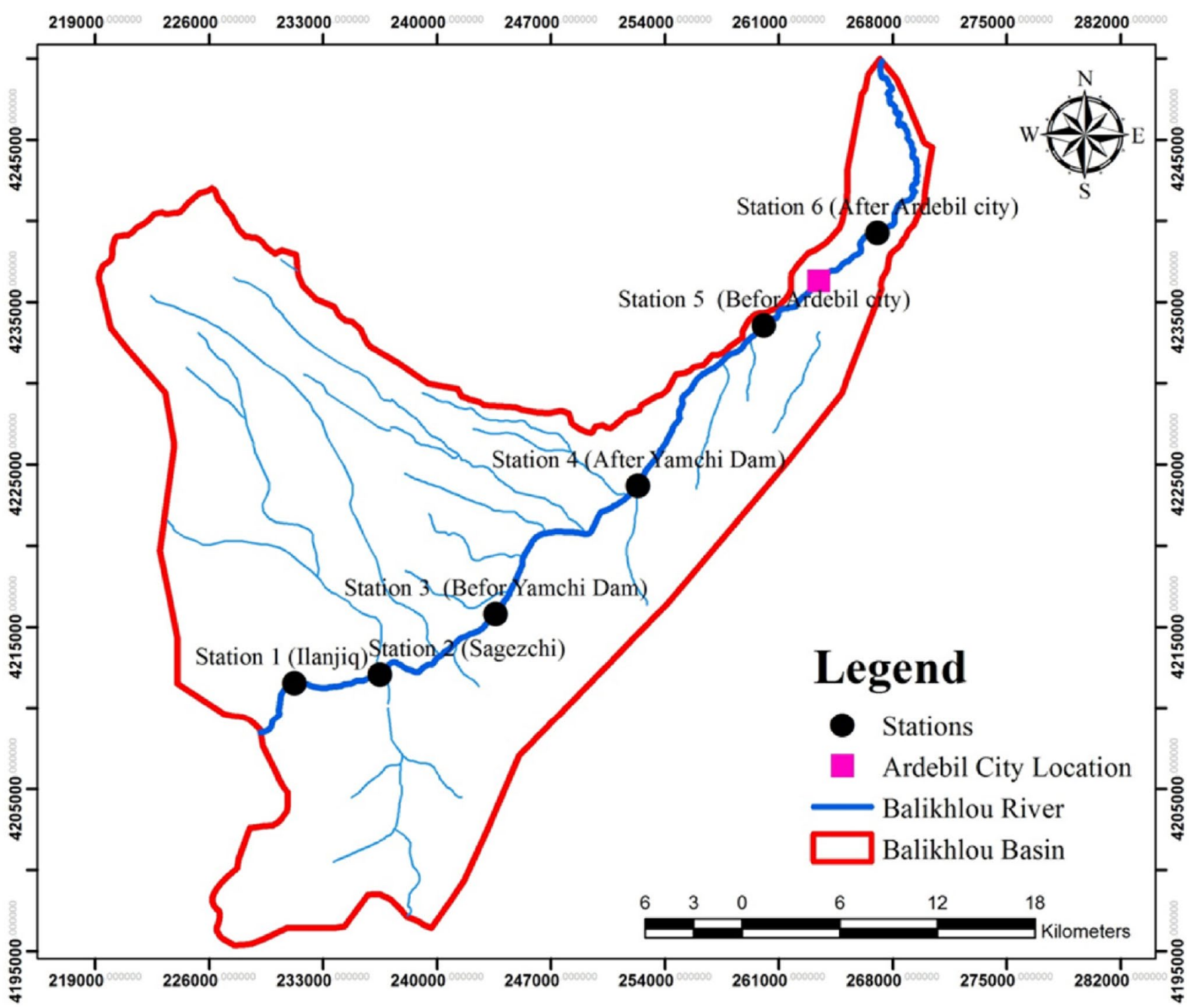

Fig. 2 The location of the five sampling stations in the study area

Table 1 Summary of statistical parameters in the area

\begin{tabular}{lllll}
\hline Parameters & \multicolumn{2}{l}{ Statistical } & & \\
\cline { 2 - 5 } & SD & Max. & Min. & Mean \\
\hline BOD $_{5}$ & 5.2632 & 16 & 4 & 6 \\
$\mathrm{No}^{3}$ & 0.9345 & 3.9 & 0.8 & 1.8 \\
TDS & 800.22 & 3710 & 42 & 714 \\
So $^{4}$ & 10.407 & 45 & 12 & 32 \\
EC & 701.58 & 2130 & 96 & 765 \\
COD & 5.0558 & 31 & 10 & 17 \\
Turbidity & 3.134 & 25 & 10.5 & 16 \\
pH & 0.7194 & 8.9 & 6.9 & 7.8 \\
\hline
\end{tabular}

Mountains and in the east are parts of the plain because Ardabil originates from the mountains that have greater elevation levels. So 72 percent of the total watershed area of the river has 1500-2500 m height (University of Tehran 1996).

The riverbed is from the above regions to the Illangigh village (range entering field of Ardabil geography) that is mountainous; it is in the bed between plains which bolt out from its full path. River length is $87 \mathrm{~km}$, its watershed is $1600 \mathrm{~km}$ and is largely mountainous. The average annual discharge of Balikhlou River water volume is 116.5 million cubic meters.

The Balikhlou River is considered the head of the main branch of the river, it goes to North after joining Aharchai in Dostbaighlo, the river is called Dare road and is interconnected to the Aras River from the east part.

Ardabil, Nir and Sarein Cities as three major urban areas are in the range of Balikhlou River watershed. These cities are a collection of rural area, thats life and culture depend 
Table 2 Different values of physicochemical parameters in different stations of year 2012

\begin{tabular}{|c|c|c|c|c|c|c|c|c|c|}
\hline \multirow[t]{2}{*}{ Data } & \multirow[t]{2}{*}{ Station } & \multicolumn{8}{|c|}{ Measurement amount of parameters } \\
\hline & & BOD 5 (mg/l) & CO D (mg/l) & $\begin{array}{l}\text { Turbidity } \\
\text { (NTU) }\end{array}$ & $\mathrm{NO}^{3}(\mathrm{mg} / \mathrm{l})$ & TDS $(\mathrm{mg} / \mathrm{l})$ & E.C $(\mu \mathrm{s} / \mathrm{cm})$ & $\mathrm{pH}$ & $\mathrm{So}^{4}(\mathrm{mg} / \mathrm{l})$ \\
\hline 2013.4.8 & Ilangigh & 6 & 10 & 13 & 1.5 & 42 & 96 & 8.6 & 12 \\
\hline 2013.7 .3 & & 5 & 10 & 13 & 1.5 & 144 & 277 & 6.9 & 12 \\
\hline 2013.12 .9 & & 4 & 14 & 14.5 & 1.3 & 148 & 310 & 7 & 14 \\
\hline 2013.1.4 & & 2 & 12 & 10.5 & 1.3 & 125 & 248 & 7.1 & 14 \\
\hline 2013.4 .8 & Borjlou & 3 & 15 & 15 & 1.9 & 258 & 535 & 8.3 & 24 \\
\hline 2013.7.3 & & 10 & 19 & 18 & 1.9 & 3710 & 342 & 7.2 & 24 \\
\hline 2013.12 .9 & & 6 & 18 & 17 & 1.8 & 1120 & 218 & 7.9 & 25 \\
\hline 2013.1.4 & & 10 & 18 & 15 & 1.5 & 854 & 1805 & 7.3 & 22 \\
\hline 2013.4 .8 & Saqezchi & 4 & 16 & 15 & 3.6 & 264 & 551 & 8.5 & 42 \\
\hline 2013.7 .3 & & 21 & 31 & 25 & 3.6 & 264 & 551 & 8.5 & 42 \\
\hline 2013.12 .9 & & 5 & 12 & 16 & 2.8 & 730 & 1500 & 7.3 & 45 \\
\hline 2013.1.4 & & 5 & 13 & 13 & 3.9 & 612 & 1293 & 7.2 & 32 \\
\hline 2013.4 .8 & Almas & 11 & 19 & 18 & 0.9 & 802 & 1648 & 8.7 & 32 \\
\hline 2013.7.3 & & 11 & 19 & 18 & 0.9 & 802 & 1648 & 8.7 & 32 \\
\hline 2013.12.9 & & 4 & 18 & 18 & 0.8 & 714 & 1470 & 7.3 & 32 \\
\hline 2013.1.4 & & 16 & 14 & 14 & 2.6 & 368 & 765 & 7.5 & 34 \\
\hline 2013.4 .8 & Ardabil city entrance & 15 & 17 & 18 & 2.3 & 912 & 1848 & 8.9 & 35 \\
\hline 2013.7.3 & & 15 & 17 & 18 & 2.3 & 912 & 1848 & 8.9 & 35 \\
\hline 2013.12 .9 & & 7 & 25 & 18.2 & 1.6 & 1010 & 2130 & 7.8 & 38 \\
\hline
\end{tabular}

on the environmental potentials of this area. The numbers of these villages, on the basis of contained information in the culture of the Ardabil Province, are 108. Figure 1 shows the position of Balikhlou River and its related field.

\section{Research parameters}

In the present research, the analysis of the water quality has been done with eight quality parameters and its quality is compared with the World Health Organization standard. Therefore, for the analysis of water quality of the river, one-way $t$ test is used. It shows the significant differences between two groups (Salehi and Porasghar Sangachin 2012). In this study, the first group contains the data which related to the samples and the second group related to national and international standards. For the research are used the water quality data of five stations that have been measured by Ardabil Province Department of Environmental Protection (Department of Environment Ardebil Province 2014). Figure 2 represents the position of the stations in the area:

For this research, eight qualitative parameters $\left(\mathrm{SO}^{4}\right.$, $\mathrm{No}^{3}$, BOD5, TDS, turbidity, $\mathrm{pH}, \mathrm{EC}$, and COD) are used. Table 1 shows a quick overview of statistical analysis such as minimum, maximum, deviation and average values of each parameter.

The statistical information relating to different periods of study stations and statistical different values is as follows (Table 2).

\section{Results}

The results of the comparison about different value measurements of 5 stations, Balikhlou river of Ardabil, in terms of WHO and IRAN standards (Standard Nos. 1091, 2010; WHO 1996; Khosto 2007; Farhadi 2013) has been shown in low-water seasons in Table 3.

As can be observed from Table 3, the average values of $\mathrm{pH}$ parameters (8.32) and turbidity (17.1) are more than WHO and Iran standards and other values of the parameters $\left(\mathrm{SO}^{4}, \mathrm{No}^{3}, \mathrm{BOD} 5, \mathrm{COD}, \mathrm{TDS}, \mathrm{EC}\right)$ in terms of national and international standards are low.

One-sample $t$ test results regarding physicochemical parameters in terms of WHO and IRAN standards in the low-water season are shown in Table 4.

The surveying results showed that measured mean difference on TDS and EC values on WHO standard and only TDS on Iran standard has more significant difference 
Table 3 Comparison of mean values of physicochemical parameters with national and international standards in summer and spring (lowwater season)

\begin{tabular}{|c|c|c|}
\hline & WHO & Iran standard \\
\hline \multicolumn{3}{|l|}{ TDS } \\
\hline Standard & 500 & 1000 \\
\hline Mean & 811 & 811 \\
\hline \multicolumn{3}{|l|}{ BOD5 } \\
\hline Standard & - & 50 \\
\hline Mean & 10.10 & 10.10 \\
\hline \multicolumn{3}{|l|}{$\mathrm{No}^{3}$} \\
\hline Standard & 10 & 50 \\
\hline Mean & 2.04 & 2.04 \\
\hline \multicolumn{3}{|l|}{ EC } \\
\hline Standard & 1000 & 1800 \\
\hline Mean & 934.4 & 934.4 \\
\hline \multicolumn{3}{|l|}{ COD } \\
\hline Standard & - & 100 \\
\hline Mean & 17.3 & 17.3 \\
\hline \multicolumn{3}{|l|}{ Turbidity } \\
\hline Standard & 0.1 & 1 \\
\hline Mean & 17.1 & 17.1 \\
\hline \multicolumn{3}{|l|}{$\mathrm{pH}$} \\
\hline Standard & $6.5-8.5$ & $6.5-8.5$ \\
\hline Mean & 8.32 & 8.32 \\
\hline \multicolumn{3}{|l|}{$\mathrm{SO}^{4}$} \\
\hline Standard & 250 & 250 \\
\hline Mean & 29 & 29 \\
\hline
\end{tabular}

(sig $>0 / 05)$. The results showed that measured means of $\mathrm{So}^{4}$, turbidity and $\mathrm{No}^{3}$ on both standards have low significance with standard amount ( $\mathrm{sig}>0 / 01$ ). Also, for $\mathrm{pH}$ values on both standards and EC on IRAN standard the mean difference is not significant $(\operatorname{sig}<0 / 05)$.

The comparison results of physicochemical parameters from WHO and IRAN standards in high-water season are shown in Table 5.

As can be observed from Table 5, the average values of the EC parameters (1082.11) and turbidity (15.133) are more than WHO standard and turbidity value is high only in Iranian standard and the values of other parameters $\left(\mathrm{SO}^{4}, \mathrm{No}^{3}, \mathrm{BOD} 5, \mathrm{COD}, \mathrm{pH}, \mathrm{TDS}\right)$ are low in terms of national and international standards.

One-sample $t$ test result regarding physicochemical parameters in terms of WHO and IRAN standards in highwater season is shown in Table 6.

The surveying result showed that measured mean difference on $\mathrm{pH}$ and $\mathrm{EC}$ is more significant in terms of WHO standard (sig $>0 / 05$ ). Also the results showed that measured means of $\mathrm{So}^{4}, \mathrm{No}^{3}$ and turbidity on WHO standard and $\mathrm{BOD}_{5}, \mathrm{COD}, \mathrm{So}^{4}, \mathrm{No}^{3}$ and turbidity on IRAN standard have
Table 4 One-sample $t$ test to compare the physicochemical values of Balikhlou River with national and international standards in lowwater season

\begin{tabular}{|c|c|c|c|c|c|}
\hline & \multirow[t]{2}{*}{ WHO } & \multirow[t]{2}{*}{ Iran standard } & \multirow[t]{2}{*}{ Mean } & \multicolumn{2}{|c|}{ Confidence } \\
\hline & & & & Lower & Upper \\
\hline \multicolumn{6}{|l|}{ TDS } \\
\hline$t$ value & -0.557 & -0.557 & -189 & 578.69 & -956.69 \\
\hline Sig & $0.591^{\mathrm{ns}}$ & $0.591^{\mathrm{ns}}$ & & & \\
\hline \multicolumn{6}{|l|}{ BOD5 } \\
\hline$t$ value & - & -21.894 & -39.9 & -35.77 & -44.02 \\
\hline Sig & - & $0.000 * *$ & & & \\
\hline \multicolumn{6}{|l|}{$\mathrm{No}^{3}$} \\
\hline$t$ value & -26.333 & -158.657 & -47.96 & -47.37 & -48.68 \\
\hline Sig & $0.000 * *$ & $* * * 0.000$ & -7.96 & -7.27 & -8.64 \\
\hline \multicolumn{6}{|l|}{$\mathrm{EC}$} \\
\hline$t$ value & -0.289 & -3.817 & -865.6 & -352.66 & -1378.53 \\
\hline Sig & $0.779^{\mathrm{ns}}$ & $0.004 *$ & -65.6 & 447.33 & -578.53 \\
\hline \multicolumn{6}{|l|}{ COD } \\
\hline$t$ value & - & -44.553 & -82.7 & -78.5 & -86.89 \\
\hline Sig & - & $0.000^{* *}$ & & & \\
\hline \multicolumn{6}{|l|}{ Turbidity } \\
\hline$t$ value & 15.455 & 14.636 & 16.1 & 18.5 & 13.61 \\
\hline Sig & $0.000 * *$ & $0.000 * *$ & 15.45 & 19.48 & 14.51 \\
\hline \multicolumn{6}{|l|}{$\mathrm{PH}$} \\
\hline$t$ value & 3.719 & 2.585 & 0.57 & 1.06 & 0.0712 \\
\hline Sig & $0.005^{*}$ & $0.029^{*}$ & 0.82 & 1.31 & 0.32 \\
\hline \multicolumn{6}{|l|}{$\mathrm{SO}^{4}$} \\
\hline$t$ value & -64.518 & -64.518 & -221.74 & -213.25 & -228.74 \\
\hline Sig & $0.000 * *$ & $* \quad 0.000 * *$ & & & \\
\hline
\end{tabular}

$* 5 \%$ difference level probability is meaningful. ** The difference in $1 \%$ probability is meaningful. ${ }^{\text {ns }}$ The mean difference is not significant

low significance with standard amount (sig $>0 / 01$ ). Also for $\mathrm{EC}$ and $\mathrm{pH}$ in terms of WHO standard, the mean difference is not significant ( $\mathrm{sig}<0 / 05)$.

Based on the obtained values of the sample analysis results that are determined with national and international standards, in the low-water season, the parameter values ( $\mathrm{pH}$, turbidity) exceed maximum specified standards and also in high-water season corresponding values (EC, Turbidity) are more than national and international standards. Figure 3 represents the number of parameters with significant and non-significant difference in high- and low-water season.

\section{Conclusion}

In this study to survey the quality of Balikhlou River as drinking water source, sampling of the physicochemical parameter changes $\left(\mathrm{SO}^{4}, \mathrm{No}^{3}, \mathrm{BOD} 5, \mathrm{COD}, \mathrm{pH}, \mathrm{EC}, \mathrm{TDS}\right.$, turbidity) in two low-water season (spring and summer) and 
Table 5 Comparison of physicochemical values with national and international standards in the fall and winter seasons (high-water season)

\begin{tabular}{|c|c|c|}
\hline & WHO & Iran standard \\
\hline \multicolumn{3}{|l|}{ TDS } \\
\hline Standard & 500 & 1000 \\
\hline Mean & 631.22 & 631.22 \\
\hline \multicolumn{3}{|l|}{ BOD5 } \\
\hline Standard & - & 50 \\
\hline Mean & 6.56 & 6.56 \\
\hline \multicolumn{3}{|l|}{$\mathrm{No}^{3}$} \\
\hline Standard & 10 & 50 \\
\hline Mean & 1.956 & 1.956 \\
\hline \multicolumn{3}{|l|}{$\mathrm{EC}$} \\
\hline Standard & 1000 & 1800 \\
\hline Mean & 1082.11 & 1082.11 \\
\hline \multicolumn{3}{|l|}{ COD } \\
\hline Standard & - & 100 \\
\hline Mean & 16 & 16 \\
\hline \multicolumn{3}{|l|}{ Turbidity } \\
\hline Standard & 0.1 & 1 \\
\hline Mean & 15.133 & 15.133 \\
\hline \multicolumn{3}{|l|}{$\mathrm{pH}$} \\
\hline Standard & $6.5-8.5$ & $6.5-8.5$ \\
\hline Mean & 3.378 & 3.378 \\
\hline \multicolumn{3}{|l|}{$\mathrm{SO}^{4}$} \\
\hline Standard & 250 & 250 \\
\hline Mean & 28.44 & 28.44 \\
\hline
\end{tabular}

high-water season (fall and winter) in five different stations of river was conducted. For this, national and international standards were used. The Iranian standard organization used standard 1053 reagent as the national standard and the World Health Organization standard was used as an international standard.

Based on results, on IRAN standard in low-water season, means of five parameter values are lower than standards and ideal ( $\mathrm{SO}^{4}, \mathrm{No}^{3}, \mathrm{COD}, \mathrm{BOD} 5$, turbidity), and two parameter values ( $\mathrm{pH}, \mathrm{EC})$ are close to standard and danger level and only amount of TDS are more than standard levels. In high-water season, five parameters $\left(\mathrm{SO}^{4}, \mathrm{BOD}_{5}\right.$, $\mathrm{No}^{3}, \mathrm{COD}$, and turbidity) are lower than standard and three parameters (TDS, EC, and $\mathrm{pH}$ ) are close to standards. In low-water seasons on WHO standard, cleared that 3 parameters values $\left(\mathrm{SO}_{4}, \mathrm{No}_{3}\right.$, Turbidity) are significant in $1 \%$ and their amount are much lower than standard and
Table 6 One-sample t test to compare the physicochemical values of Balikhlou River water with national and international standards in high-water season

\begin{tabular}{|c|c|c|c|c|c|}
\hline & \multirow[t]{2}{*}{ WHO } & \multirow[t]{2}{*}{ Iran standard } & \multirow[t]{2}{*}{ Mean } & \multicolumn{2}{|c|}{ Confidence } \\
\hline & & & & Lower & Upper \\
\hline \multicolumn{6}{|l|}{ TDS } \\
\hline$t$ value & -3.117 & -3.117 & -368.77 & -95.92 & -641.63 \\
\hline Sig. & $* 0.014$ & $* 0.014$ & & & \\
\hline \multicolumn{6}{|l|}{ BOD5 } \\
\hline$t$ value & - & -31.131 & -43.44 & -40.22 & -46.66 \\
\hline Sig. & - & $* * 0.000$ & & & \\
\hline \multicolumn{6}{|l|}{$\mathrm{No}^{3}$} \\
\hline$t$ value & -24.988 & -149.238 & -48.04 & -47.30 & -48.78 \\
\hline Sig. & $* * 0.000$ & $* * 0.000$ & -8.04 & -7.3021 & -8.7848 \\
\hline \multicolumn{6}{|l|}{$\mathrm{EC}$} \\
\hline$t$ value & 0.343 & -2.998 & -717.88 & -165.64 & -1270.13 \\
\hline Sig. & ${ }^{\mathrm{ns}} 0.741$ & $* 0.017$ & 82.11 & 634.25 & -470.13 \\
\hline \multicolumn{6}{|l|}{ COD } \\
\hline$t$ value & - & -59.814 & -84 & -80.76 & -87.23 \\
\hline Sig. & - & $* * 0.000$ & & & \\
\hline \multicolumn{6}{|l|}{ Turbidity } \\
\hline$t$ value & 18.116 & 17.032 & 14.13 & 16.04 & 12.21 \\
\hline Sig. & $* * 0.000$ & $* * 0.000$ & 15.03 & 16.94 & 13.11 \\
\hline \multicolumn{6}{|l|}{ PH } \\
\hline$t$ value & -1.209 & -3.683 & -0.3722 & -0.1391 & -0.6053 \\
\hline Sig. & ${ }^{\mathrm{ns}} 261 / 0$ & $* 0.006$ & -0.122 & 0.1109 & -0.35553 \\
\hline \multicolumn{6}{|l|}{$\mathrm{SO}^{4}$} \\
\hline$t$ value & $938 / 62-$ & -62.938 & -221.55 & -213.43 & -229.67 \\
\hline Sig. & $* * 0.000$ & $* * 0.000$ & & & \\
\hline
\end{tabular}

$* 5 \%$ difference level probability is meaningful. ** The difference in $1 \%$ probability is meaningful. ${ }^{\text {ns }}$ The mean difference is not significant

parameter values $(\mathrm{pH})$ at 5 percent is close to the standard and risk threshold, But (TDS, EC) parameters are much higher than standard and show the danger limit. In general, it can be stated that the different measurement of TDS and EC in terms of WHO standard and TDS on Iran standard in low-water season and $\mathrm{pH}$ and EC parameters in terms of WHO standard on high-water season are not significant. Therefore, it represents high and closeness of average parameters to the standards and shows the risk limit of river water. The pararmeters which are higher than the standards in the region, these reason can be the contaminants sources, that derived from agricultural activities and human sewage (Ardabil, Nir and Sarein cities) absorbed 
Fig. 3 The number of parameters and quality changes based on national and international standards during different seasons

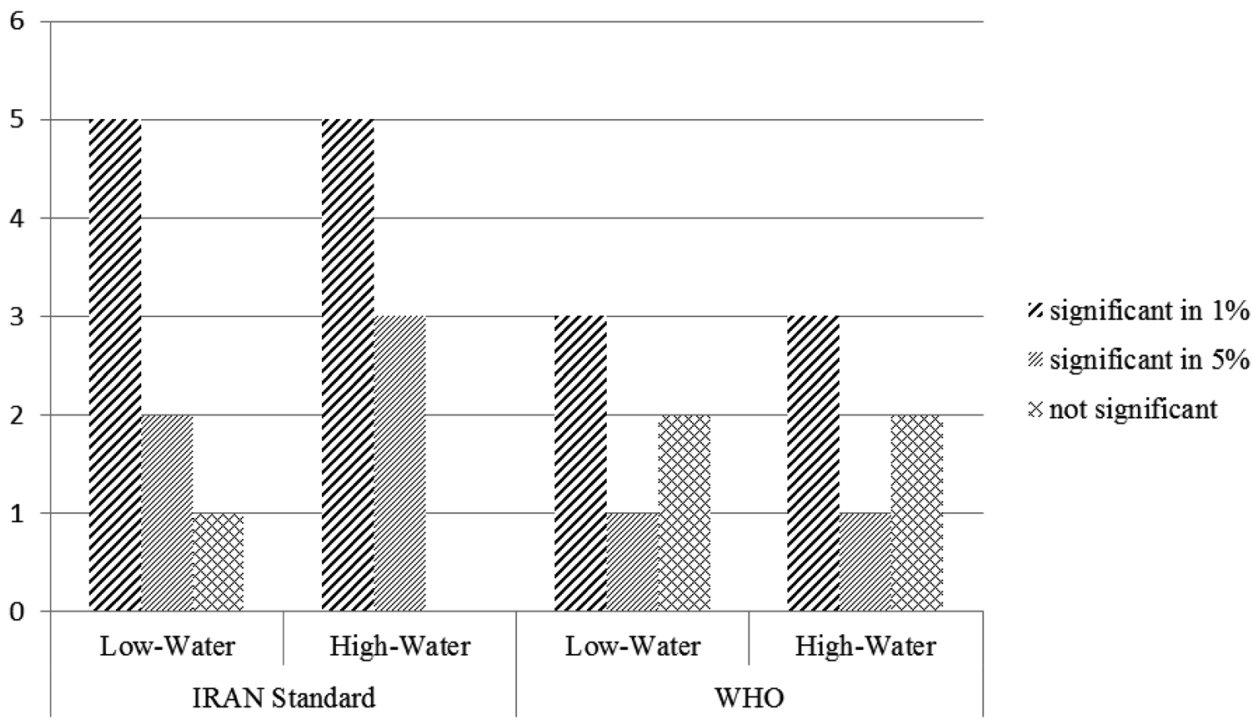

through the area wells that in low-water season because of decrease of water capacity and increase their amounts.

Open Access This article is distributed under the terms of the Creative Commons Attribution 4.0 International License (http://creativeco mmons.org/licenses/by/4.0/), which permits unrestricted use, distribution, and reproduction in any medium, provided you give appropriate credit to the original author(s) and the source, provide a link to the Creative Commons license, and indicate if changes were made.

\section{References}

Chen Y, Chen M (2001) Heavy metal concentration in nine species of fishes caught in costal waters off Ann-Ping, S.W. Taiwan. Journal of Food and Drug Analysis. 9:107-114

Department of Environment Ardebil Province (2014) Periodic measurements of the river, the Deputy of monitoring, not printed information

Farhadi H (2013) Review and determine of the nitrates polluting sources in drinking water of Ardabil villages. Master thesis, Islamic Azad University, Ardabil Branch

Hajian Nejad M, Rahsepar AR (2010) nvestigation of effect of city of Isfahan and effl uent from Isfahan wastewater treatment plant on some of Zayandeh Rood river water quality parameters. J Health Syst Res 6:821-828

Huang S, Chen D (2009) Rapid removal of heavy metal cations and anions from aqueous solutions by anamino-functionalized magnetic nano-adsorbent. J Hazard Mater 163:174-179

Khadam IM, Kaluarachchi JJ (2006) Water quality modeling under hydrologic variability and parameter uncertainty using erosionscaled export coefficients. J Hydrol 330:354-367

Khosto H 2007) Qualitative modeling of Tehran Province underground water sources (case study: Islamshar villages), Master Thesis, Islamic Azad University, Science and Research
Meybeck M (2003) Global analysis of river systems: from earth system controls to anthropocene syndromes. Philos Trans R Soc Lond B 358:1935-1955

Miranzadeh MB, Mahmodzadeh A, Hasan Zadeh M, Bigdeli M (2011) Concentrations of heavy metals in Kashan Water distribution network in 2010. J Health 2(3):56-66

Nouri RF, Jafari FA, Akbarzadeh A (2011) Suitable framework to check the quality of Atrek border river. Health Environ J Sci Res J Environ Health Commun 4(2):159-170

Ouyang Y (2005) Evalution of river water quality monitoring stations by principal component analysis. Water Res 39:2621-2635

Rajaei Q, Pourkhabaz A, Motlag S (2012) Assessment of heavy metals health risk of groundwater in Ali Abad Katoul Plian. J N Khorasan Univ Med Sci 4(2):155-162

Salehi I, Porasghar Sangachin F (2012) Methodology in environmental science and its application in student projects, published by Stuart Herald, Lazuli Batik, Miryam Diamund, George Aronditis. University of Tehran publications, Tehran

Sedaghat M (2008) Earth and water resourcees (Groundwater). Payame Noor University Publication, Tehran

Standard No, 1053 (2010) The instructions and measurement methods of physicochemical agents and toxic inorganic chemicals in drinking water

University of Tehran (1996) Sustainable impact on Ardebil Province environment. Geography Institue, Tehran

WHO (1996) Guidline for drinking water quality, vol 2, 2nd edn. WHO, Geneva

Publisher's Note Springer nature remains neutral with regard to jurisdictional claims in published maps and institutional affiliations. 